\title{
KINETIC ANALYSIS OF BATCH ETHANOL ACETYLATION IN ISOTHERMAL NON-STATIONARY MULTIPHASE SYSTEMS BY LYOPHILIZED MYCELIUM OF ASPERGILLUS ORYZAE
}

\author{
Emilio Palazzi ${ }^{1}$, Francesco Molinari ${ }^{2}$, Bruno Fabiano ${ }^{1}$, Adalberto Pessoa $\mathbf{J r}^{3}$, Attilio Converti ${ }^{1 *}$ \\ ${ }^{1}$ Department of Chemical and Process Engineering “G.B. Bonino”, University of Genoa, via Opera Pia 15 - 16145 Genoa, Italy; \\ ${ }^{2}$ Department of Food and Microbiological Science and Technology, University of Milan, Italy; ${ }^{3}$ Departamento de Tecnologia \\ Bioquímico-Farmacêutica, Universidade de São Paulo, São Paulo, SP, Brasil.
}

Submitted: March 16, 2010; Approved: June 21, 2010.

\begin{abstract}
A relatively complex network of reactions has been investigated, using as a network model the isothermal batch esterification of acetic acid with ethanol in $n$-heptane catalyzed by lyophilized mycelium of Aspergillus oryzae. The kinetic analysis was firstly carried out on the whole system, without any simplification, by means of the well-known integral method. Owing to the poor results obtained by this way, we developed an alternative approach, combining initial rates and integral analysis and reducing the number of empirical parameters to be determined by the use of equilibrium data. All the values of the parameters calculated according to this "composite" approach to kinetic analysis well correlate with experimental data.
\end{abstract}

Key words: Aspergillus oryzae, Complex network, Enzyme reactions, Esterification, Organic solvent

\section{INTRODUCTION}

The study of any reaction network in isothermal, nonsteady-state systems could be carried out, in principle, by means of the integral method of kinetic analysis. As is known, such a method allows estimating, by regression, the parameters of a model using the experimental values of concentrations of the involved components along the time.

However, the results obtained by the integral approach are often scarcely useful for practical purposes, especially in the case of complex reaction networks and multiphase systems, when the correlation between model and experimental data is poor, or else when the values of some parameters are meaningless. Moreover, different values of these could fit equally well with experimental results, making it difficult to select the most reliable set of data.

Nevertheless, the effectiveness of the integral method can be greatly enhanced by reducing the number of parameters to be determined. This option doesn't necessarily require a simplification of the model, but it can also be done by direct calculation of some of the parameters by different methods and/or using chemical equilibrium data. These topics are discussed in the present work, taking as a reference model the esterification of acetic acid with ethanol in $n$-heptane, catalyzed by lyophilized mycelium of Aspergillus oryzae.

Various innovative processes of bioesterification in hydrophobic environment were extensively studied, making use of batch, isothermal reactors and different combinations of 
reagents, enzymes, organic solvents and operating conditions (2-4, 8-12), because most of them allow the enantiomeric resolution of racemic compounds of pharmaceutical significance, among which solketal (12), ketoprofen and ibuprofen (1).

Chemical transformations occurring in these systems are well described by the so-called "ping-pong" mechanism proposed by Yang and Russell (13), which is opposite to that presented by Jencks (7) for esters hydrolysis in water. Substitution of water with organic solvents, useful to move the chemical equilibrium towards the ester production, somewhat complicates some physical aspects of the kinetics, owing to the formation of different phases in the reacting fluid.

In previous works $(2,4)$, we studied the process kinetics applying the method of the initial rates to a simplified form of the model, so as to obtain results useful for practical applications. Some of these results are used here, implemented with equilibrium data, in order to simplify the kinetic analysis of the general, more comprehensive model, by means of the integral method.

\section{MATERIALS AND METHODS}

Chemicals, mycelium preparation, procedures and analytical methods were previously described $(2,4,10)$. The optimal process conditions were previously determined by an extensive experimental work, performed at different temperatures and concentrations of the lyophilized mycelium of Aspergillus oryzae MIM and substrates, and a simplified kinetic model based on the method of the initial rates was successfully used $(2,4)$. The kinetic investigation is extended in this work to the overall duration of the process, so as to evaluate the whole set of model parameters. All bioconversions were performed in triplicate at a temperature of $50{ }^{\circ} \mathrm{C}$ and using a lyophilized mycelium of Aspergillus oryzae MIM as a catalyst at concentrations of 10 and $20 \mathrm{~g} / \mathrm{L}$.

\section{THEORY}

Under particular circumstances, a rather complex network of reactions can be studied in a relatively simple way. The case of ethanol acetylation by mycelium-bound carboxylesterase of Aspergillus oryzae is chosen in this work as an example. The process was performed in organic solvent ( $n$-heptane) $(2,4,10)$ to shift the chemical equilibrium towards the esterification (6). The involved reaction network, corresponding to the so-called ping-pong mechanism (13), is:

$$
\begin{gathered}
k_{1} \\
\mathrm{E}+\mathrm{A} \leftrightarrow \mathrm{E}_{\mathrm{A}}+\mathrm{W} \\
k_{1}^{\prime} \\
k_{2} \\
\mathrm{E}_{\mathrm{A}}+\mathrm{B} \leftrightarrow \mathrm{E}_{\mathrm{P}} \\
k_{2}^{\prime} \\
k_{3} \\
\mathrm{E}_{\mathrm{P}} \leftrightarrow \mathrm{E}+\mathrm{P} \\
k_{3}^{\prime}
\end{gathered}
$$

where $\mathrm{E}$ is the active free enzyme, $\mathrm{A}$ the acetic acid, $\mathrm{B}$ the ethanol, $\mathrm{P}$ the ethyl acetate, $\mathrm{E}_{\mathrm{A}}$ and $\mathrm{E}_{\mathrm{P}}$ the complexes of the enzyme with acetic acid and ethyl acetate, respectively, $\mathrm{W}$ the water, while $k_{1}, k_{2}, k_{3}$ are the specific rate constants of the direct reactions (1-3) and $k_{1}^{\prime}, k_{2}^{\prime}, k_{3}$ those of their respective inverse reactions.

Taking into accounts Equations (1-3), A, B and P balances can be written as:

$$
\begin{aligned}
& d A / d t=-k_{1} E A+k_{1}^{\prime} E_{A} W \\
& d B / d t=-k_{2} E_{A} B+k_{2}^{\prime} E_{P} \\
& d P / d t=k_{3} E_{P}-k_{3}{ }_{3} E P
\end{aligned}
$$

the italic symbols of the chemical species representing their molar concentrations.

Because at the beginning of the process are $E_{A 0}=E_{P 0}=P_{0}$ $=0$, the concentrations of the complexed and free enzyme at any instant are given by:

$$
\begin{aligned}
& E_{A}=A_{0}-A+B-B_{0} \\
& E_{P}=B_{0}-B-P \\
& E=E_{0}+A-A_{0}+P
\end{aligned}
$$


Starting from the water balance in the phase where the reaction takes place:

$W=W_{0}+A_{0}-A-K_{r} W$

one can write:

$W=\left(W_{0}+A_{0}-A\right) /\left(1+K_{r}\right)$

where $K_{r} W$ is the molar concentration of water in the nonreacting phase and $K_{r}$ the corresponding partition coefficient.

Substitution of Equations (7-9) and (11) into Equations (4-6) gives:

$d A / d t=-k_{1} E_{0} A-k_{1} A\left(E-E_{0}\right)+k^{\prime}{ }_{1} * W_{0} E_{A}+k^{\prime}{ }_{1} * E_{A}\left(A_{0}-A\right)$

$d B / d t=-k_{2} B E_{A}+k_{2}^{\prime} E_{P}$ $d P / d t=k_{3} E_{A}-k_{3}{ }_{3} E_{P} P$

where:

$k^{\prime}{ }_{1}^{*}=k^{\prime}{ }_{1} /\left(1+K_{r}\right)$

\section{RESULTS AND DISCUSSION}

Figures 1 and 2 show the results of ethanol acetylation obtained under optimal operating conditions, i.e.: $T=50^{\circ} \mathrm{C}$, concentration of the lyophilized mycelium, $C_{M}$, of 10 and 20 $\mathrm{g} / \mathrm{L}$, respectively. In fact, as previously stressed, under these conditions, the effect of enzyme inactivation can reasonably be neglected $(2,4)$.

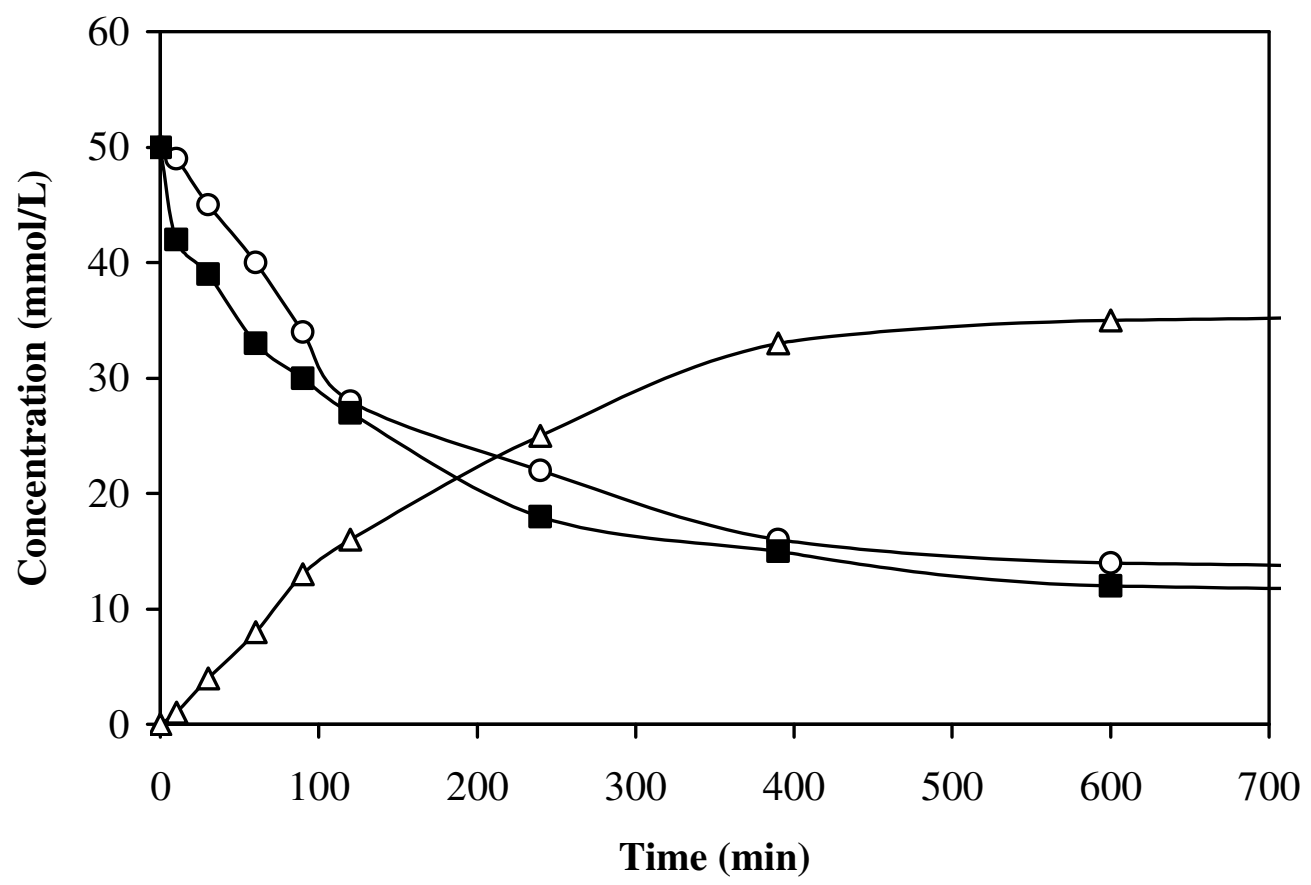

Figure 1. Experimental results of ethanol acetylation performed at $50^{\circ} \mathrm{C}$ with lyophilized mycelium of $A$. oryzae at concentration of $10 \mathrm{~g} / \mathrm{L}$. (O) Acetic acid; $(\boldsymbol{\square})$ ethanol; $(\triangle)$ ethylacetate. Starting conditions: acetic acid $50 \mathrm{mmol} / \mathrm{L}$; ethanol $50 \mathrm{mmol} / \mathrm{L}$. Equilibrium conditions were obtained after $2880 \mathrm{~min}$ as follows: acetic acid $9 \mathrm{mmol} / \mathrm{L}$; ethanol $11 \mathrm{mmol} / \mathrm{L}$; ethylacetate 38 $\mathrm{mmol} / \mathrm{L}$. 


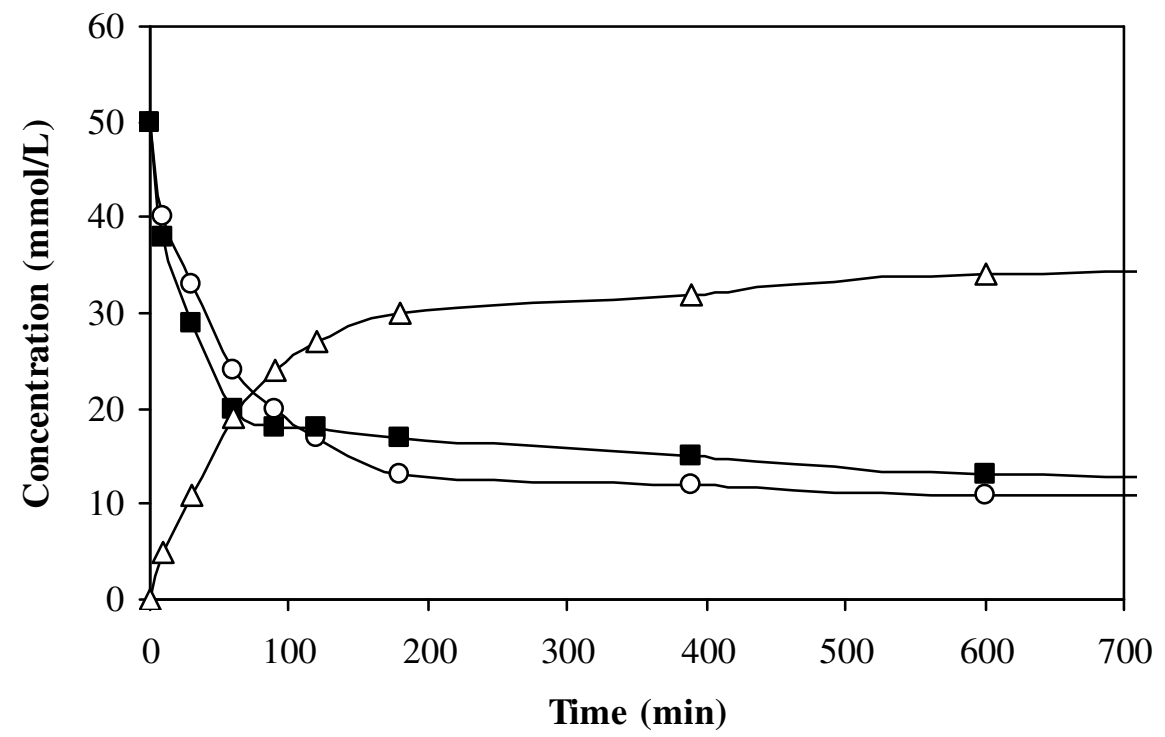

Figure 2. Experimental results of ethanol acetylation performed at $50^{\circ} \mathrm{C}$ with lyophilized mycelium of $A$. oryzae at concentration of 20 g/L. (O) Acetic acid; (ם) ethanol; $(\triangle$ ) ethylacetate. Starting conditions: acetic acid $50 \mathrm{mmol} / \mathrm{L}$; ethanol $50 \mathrm{mmol} / \mathrm{L}$. Equilibrium conditions were obtained after $2880 \mathrm{~min}$ as follows: acetic acid $8 \mathrm{mmol} / \mathrm{L}$; ethanol $10 \mathrm{mmol} / \mathrm{L}$; ethylacetate $37 \mathrm{mmol} / \mathrm{L}$.

\section{Integral method}

As already remarked, the study of the process kinetics was firstly performed by means of the integral method (5), which requires formally integrating Equations (12-14) with respect to time:

$A_{t}-A_{0}=-k_{1} E_{0} \int_{0}^{t} A d t-k_{1} \int_{0}^{t} A\left(E-E_{0}\right) d t+k^{\prime}{ }_{1} * W_{0} \int_{0}^{t} E_{A} d t+$

$+k_{1}{ }_{1} * \int_{0}^{t} E_{A}\left(A_{0}-A\right) d t$

$B_{t}-B_{0}=-k_{2} \int_{0}^{t} B E_{A} d t+k_{2}^{\prime} \int_{0}^{t} E_{P} d t$

$P_{t}=k_{3} \int_{0}^{t} E_{P} d t-k_{3} E_{0} \int_{0}^{t} P d t-k_{3}{ }_{3} \int_{0}^{t} P\left(E-E_{0}\right) d t$

then numerically calculating the integrals in Equations (16-18), taking into accounts Equations (7-9) and the experimental data, and finally estimating by linear regression the parameters appearing in Equations (16-18).

Unfortunately, the values of some parameters resulted to be meaningless (e.g., $k_{3}^{\prime}<0$ ), probably due to the limitations of the method mentioned in the Introduction. Therefore, as discussed in the next session, a different approach is developed, presenting a two-step analysis as a tool for estimation of all relevant kinetic parameters.

\section{Two-step method}

The method adopted to calculate the kinetic parameters is based on the possibility of splitting the whole process into two stages. According to the experimental results, up to few tenths of minutes since the beginning of the esterification, the predominant reaction is certainly the attack of acetic acid to the active site of the enzyme, so the kinetics can be adequately described by Equations (4) and (9).

Making reference to the first $30 \mathrm{~min}$ of the process, where $P \cong 0$ and $W \cong W_{0} \cong 0$, since the biocatalyst is lyophilized, combination of Equations (4) and (9) gives:

$d A / d t=-k_{1} A\left(E_{0}+A-A_{0}\right)$

By integration, one can obtain:

$$
A=A_{o} \frac{\left(E_{o}-A_{o}\right) \exp \left[-k_{1}\left(E_{o}-A_{o}\right) t\right]}{E_{o}-A_{o} \exp \left[-k_{1}\left(E_{o}-A_{o}\right) t\right]}
$$

From the experimental results obtained under the optimal conditions, we then estimated the values of the parameters $k_{1}$ and $\mathrm{E}_{\mathrm{o}}$ listed in Table 1. 
Table 1. Kinetic constant of acetylation and concentration of the active free enzyme.

\begin{tabular}{|c|c|c|}
\hline$C_{M}\left(\mathrm{~g} \mathrm{~L}^{-1}\right)$ & $k_{1}\left(\mathrm{~L} \mathrm{mmol}^{-1} \mathrm{~h}^{-1}\right)$ & $E_{0}\left(\mathrm{mmol} \mathrm{L}^{-1}\right)$ \\
\hline 10 & 0.161 & 11.4 \\
\hline 20 & 0.133 & 23.3 \\
\hline
\end{tabular}

As it can be seen, the values of $\mathrm{k}_{1}$ are comparable one to the other, while those of the concentration of the active free enzyme are nearly proportional to the ones of the mycelium used in the runs. As regards the next phase of the process, the results demonstrate that equilibrium conditions $(\mathrm{dA} / \mathrm{dt}=\mathrm{dB} / \mathrm{dt}$ $=\mathrm{dP} / \mathrm{dt}=0$ ) were achieved after about 2 days, so:

$A=A_{\infty} ; B=B_{\infty} ; P=P_{\infty}$

$E_{\mathrm{A}}=E_{A_{\infty}}=A_{0}-A_{\infty}+B_{\infty}-B_{0}$

$E_{\mathrm{P}}=E_{\mathrm{P} \infty}=B_{0}-B_{\infty}-P_{\infty}$

$E=E_{\infty}=E_{0}+A_{\infty}-A_{0}+P_{\infty}$

Then we obtain from Equations (12-14):

$$
\begin{aligned}
& k^{\prime}{ }_{1}^{*}=k_{1} A_{\infty} E_{\infty} /\left[\left(A_{0}-A_{\infty}\right) E_{A \infty}\right] \\
& k^{\prime}{ }_{2}=k_{2} B_{\infty} E_{A \infty} / E_{P \infty} \\
& k^{\prime}{ }_{3}=k_{3} E_{P \infty} /\left(P_{\infty} E_{\infty}\right)
\end{aligned}
$$

The value of $k_{1}{ }^{*}$ was directly calculated by Equation (25). As far as the other parameters are concerned, substitution of Equations (26-27) into Equations (17-18) gives:

$$
\begin{aligned}
& B_{t}-B_{0}=k_{2} \int_{0}^{t}\left(B_{\infty} E_{A \infty} E_{\mathrm{P}} / E_{\mathrm{P} \infty}-B E_{A}\right) d t \\
& P_{t}=k_{3} \int_{0}^{t}\left[E_{P}-E_{P \infty} E P /\left(P_{\infty} E_{\infty}\right)\right] d t
\end{aligned}
$$

The kinetic constants $k_{2}$ and $k_{3}$ were then calculated by means of the integral method, and, finally, $k_{2}^{\prime}$ and $k_{3}^{\prime}$ by Equations (26) and (27), respectively. Table 2 lists all the values estimated for these parameters.

The developed analysis allowed calculating in a simple and reliable way all the relevant kinetic parameters of the

\begin{tabular}{|c|c|c|c|c|c|}
\hline $\begin{array}{c}C_{M} \\
\left(\mathrm{~g} \mathrm{~L}^{-1}\right)\end{array}$ & $\begin{array}{c}k_{1}^{\prime}{ }^{*} \\
\left(\mathrm{~L} \mathrm{mmol}^{-1} \mathrm{~h}^{-1}\right)\end{array}$ & $\begin{array}{c}k_{2} \\
\left(\mathrm{~L} \mathrm{mmol}^{-1} \mathbf{h}^{-1}\right)\end{array}$ & $\begin{array}{l}k_{2}^{\prime} \\
\left(\mathbf{h}^{-1}\right)\end{array}$ & $\begin{array}{c}k_{3} \\
\left(\mathbf{h}^{-1}\right)\end{array}$ & $\begin{array}{c}k_{3}^{\prime} \\
\left(\mathbf{L ~} \mathrm{mmol}^{-1} \mathbf{h}^{-1}\right)\end{array}$ \\
\hline 10 & 0.30 & 0.32 & 2.1 & 9.6 & 0.060 \\
\hline 20 & 0.28 & 0.35 & 1.9 & 11.0 & 0.049 \\
\hline
\end{tabular}
reaction network, including conventional rate constant and "pseudo kinetic" rate parameters, accounting for the active free enzyme concentration $\left(k_{1}^{\prime}{ }_{1}^{*}\right.$ and $\left.k_{3}{ }_{3}\right)$.

Table 2. Kinetic parameters of the process steps following enzyme acetylation.

\section{CONCLUSIONS}

A two-step approach was proposed to analyze complex enzyme reaction networks in a multiphase system. Applicability of the method was demonstrated in the reaction scheme of bioesterification of acetic acid with ethanol in $n$ - heptane, catalyzed by lyophilized mycelium of Aspergillus oryzae. The first step of the framework considered as key reaction the attack of acetic acid to the active site of the enzyme; the subsequent step was based on the integral method, applied at the equilibrium conditions and allowed estimating all the kinetic parameters of the complete model. Such a novel approach could also be applied to other similar cases, 
overcoming possible incongruities of the well-established integral method.

\section{REFERENCES}

1. Carvalho, P.O.; Contesini, F.J.; Ikegaki, M. (2006). Enzymatic resolution of $(\mathrm{R}, \mathrm{S})$-ibuprofen and $(\mathrm{R}, \mathrm{S})$-ketoprofen by microbial lipases from native and commercial sources. Braz. J. Microbiol. 37(3), 329-337.

2. Converti, A.; Del Borghi, A.; Gandolfi, R.; Lodi, A.; Molinari, F.; Palazzi, E. (2002). Reactivity and stability of mycelium-bound carboxylesterase from Aspergillus oryzae. Biotechnol. Bioeng. 77, 231237.

3. Converti, A.; Del Borghi, A.; Gandolfi, R.; Molinari, F.; Palazzi, E.; Perego, P.; Zilli, M. (2002). Simplified kinetics and thermodynamics of geraniol acetylation by lyophilized cells of Aspergillus oryzae. Enzyme Microb. Technol. 30, 216-223.

4. Converti, A.; Del Borghi, M.; Gandolfi, R.; Molinari, F.; Palazzi, E.; Zilli, M. (2002). Ethanol acetylation by mycelium-bound carboxylesterase of Aspergillus oryzae: estimation of thermodynamic parameters and integral productivity. World J. Microbiol. Biotechnol. 18, 409-416.

5. Froment, G.F.; Bischoff, K.B. (1990). Chemical Reactor Analysis and Design. Wiley \& Sons, New York, USA.

6. Halling, P.J. (1994). Thermodynamic predictions for biocatalysis in non conventional media: theory, tests and recommendations for experimental design and analysis. Enzyme Microb. Technol. 16, 178-206.

7. Jencks, W.P. (1987). Catalysis in Chemistry and Enzymology. Dover, New York, USA.

8. Lojudice, F.H.; Silva, D.P.; Zanghin, N.I.T.; Pessoa, A. (2001). Overexpression of glucose-6-phosphate dehydrogenase in genetically modified Saccharomyces cerevisiae. Appl. Biochem. Biotechnol. 91(3), 161-169

9. Molinari, F.; Gandolfi, R.; Aragozzini, F. (1996). Microbial catalyzed esterification of primary and secondary alcohols in organic solvent. Biotechnol. Techniques 10. 103-108.

10. Molinari, F.; Gandolfi, R.; Aragozzini, F.; Converti, A.; Zilli, M. (2000). Mycelium-bound carboxylesterase from Aspergillus oryzae: an efficient catalyst for acetylation in organic solvents. Enzyme Microb. Technol. 27, 626-630.

11. Pessoa, A.; Vitolo, M. (1998). Evaluation of cross-flow microfiltration membranes using a rotary disc-filter. Process Biochem. 33(1), 39-45.

12. Romano, D.; Ferrario, V.; Molinari, F.; Gardossi, L.; Sanchez Montero, J.M.; Torre, P.; Converti, A. (2006). Kinetic resolution of (R,S)-1,2-Oisopropyldeneglycerol by esterification with dry mycelia of moulds. $J$. Mol. Catal. B-Enzym. 41, 71-74.

13. Yang, Z.; Russell, A.J. (1996). Fundamentals of non-aqueous enzymology. In: Koskinen, A.M.P., Klibanov, A.M. (eds). Enzymatic Reactions in Organic Media. Chapman \& Hall, London, UK, p. 43-69. 